\title{
An Anthropo-Based Standpoint on Mediating Objects: Evolution and Extension of Industrial Design Practices
}

\author{
Catherine Elsen $^{1}$, Françoise Darses ${ }^{2}$ and Pierre Leclercq ${ }^{1}$ \\ ${ }^{1}$ University of Liège, Belgium \\ ${ }^{2}$ University of Paris Sud, France
}

This paper questions the new uses of design tools and representations in the industrial field. A two months in situ observation of real industrial practices shows (i) how strongly CAD (Computer-Aided Design) tools are integrated in work practices, in preliminary design phases as well, and (ii) how design actors sometimes deviate this tool from its initial objectives to use it in complement of sketches' contributions. A multi-layered study built on an anthropo-based approach helps us to deepen the "mediating objects" analysis. It also suggests considering the complementarities of design tools instead of their differences in order to propose another kind of design support tool.

\section{Introduction - a Shift in Design Tools' Consideration}

Research in the design field deals with numerous topics, among which the support of early stage processes in design, that has gathered a lot of attention in architecture, industrial or mechanical design. Distinct communities emerge: some of them improve CAD (Computer-Aided Design) tools to carry through "quick and dirty" representations; others make SBIM (Sketch Based Interfaces for Modeling) more efficient; or enlarge sketch potentials. The argumentation principle in literature is more or less similar. Most of the authors list sketches' advantages or shortcomings as well as CAD tools' powers or limitations to support ideation, Table 1. The core of the comparison lies at the "end of the preliminary design stage", usually defined as the shift from free-hand sketching to Computer-Aided Design detailed drawing [1]. This comparison of the two design tools' benefits and 
limitations enables the authors to finally confront them (free-hand sketches versus Computer Aided Design tools), before presenting one own technical, methodological or theoretical proposition.

Table 1 (continued next page) Free-hand sketch and CAD tool pros and cons

\begin{tabular}{|c|c|}
\hline \multicolumn{2}{|c|}{ Free-hand sketch } \\
\hline & $\begin{array}{l}\text { is fast, easy, allows an efficient problem/solution exploration through } \\
\text { minimal content [2] } \\
\text { makes easier the apprehension of complex and wide problem space } \\
\text { allows unexpected discoveries through its high opportunist aspects } \\
\text { [3] and the "see-transform-see" mechanisms [4], keeping the } \\
\text { exploration dynamic } \\
\text { allows different levels of abstraction [2] and a certain ambiguity } \\
\text { (incoherencies between several representations of a same object are } \\
\text { allowed) [5] } \\
\text { enables a "width" strategy (exploration of more alternatives) [6] } \\
\text { constitutes a "paper memory" : deletion is never totally completed } \\
\text { lightens spatial memory load [7]; constitutes a real "external working } \\
\text { memory" relieving the internal short-term memory from additional } \\
\text { cognitive costs; is a mnemonic help [8] } \\
\text { supports communication and construction of common reference } \\
\text { systems [9] } \\
\text { stays a natural, intuitive and traditional "interface" }\end{array}$ \\
\hline & $\begin{array}{l}\text { is lacunar, ambiguous, highly personal with complex, implicit } \\
\text { content and low level of structuration, stays rigid and static (non- } \\
\text { reactive representation) } \\
\text { has a slow production-time (although it can help to mature ideas and } \\
\text { get "insights") }\end{array}$ \\
\hline & mputer \\
\hline & $\begin{array}{l}\text { very powerful tool for feasibility studies : allows to calculate, } \\
\text { imize, simulate any kind of reaction to multiple constraints } \\
\text { ysical constraints, production constraints, ...) and to reach high } \\
\text { els of complexity } \\
\text { bles a relatively quick access to 3D visualization for evaluation } \\
\text { es modifications through parametrizing } \\
\text { es technical communication and data exchanges through formats' } \\
\text { fication } \\
\text { netimes leads to positive premature fixation }[10]\end{array}$ \\
\hline
\end{tabular}


Table 1 (continued)

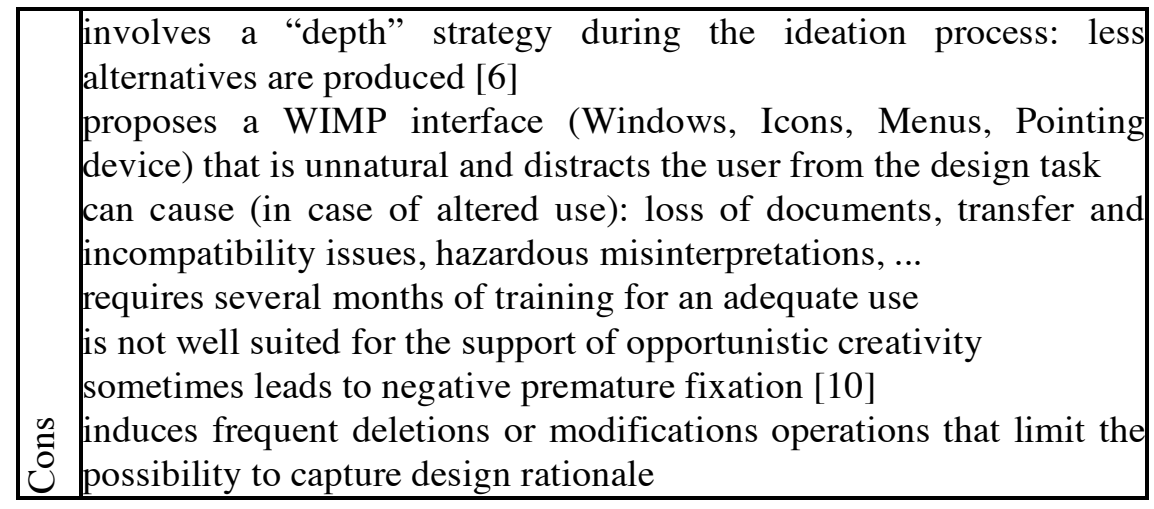

Whatever the point of view, both tools present respective particularities that can (in)efficiently equip the design process. Less is said nevertheless about how designers effectively exploit these tools: how do they select them, and according to which characteristics ? is this choice subjected to changes all along the process ? and what are the specificities of these changes? which factors do "shape" the use of design tools ? On the other hand, free-hand sketches are considered as more "traditional" than CAD tools. How have these "new" design tools impacted the everyday work practices?

To answer these questions, our paper suggests that once a tool is integrated in work practices - whatever its pros and cons - there is a reciprocal impact of, on the one hand, the adaptation of the tool and, on the other hand, the evolution of work practices.

Moreover, a new tool should not be considered as impairing the work but rather as enriching what already exists. In other words, we suggest that it is not worth considering free-hand sketch against CAD tools, since these "mediating tools" are useful and complementary in their respective contributions. The paper will show that CAD tools are indeed now fully integrated in designers' work practices while free-hand sketches remain a powerful design tool. This observation also questions the widening of the traditional borders of "the early stage of design" and its "traditional tools".

To better understand these "mediating tools" evolutions and modulations, we examine various factors, such as operating methods, collaborative modalities or cognitive demands all along the design process. The next section will present the theories that structure this examination, while the third section will detail our methodologies. We will then present our main observations and test our previous suggestions. Our hope is that 
our multidisciplinary approach contributes to a more effective convergence to "augmented design tools" that stay closer to real practices.

\section{Rationale of the Study: Understanding the Use of Design Tools through a Three Phases Proposition}

Several schools of thought appear in research on design tools. The first one holds the situation just as it is: sketches are powerful for preliminary design, CAD tools for detailed design. Mitchell \& al [11] share this conservative point of view. They argue that "because creativity is associated with novelty, comprehensive computer tools for creative work will be neither possible nor necessary to develop, any more than it is necessary for a pencil to include all functions for drawing". For this community, CAD tools are not considered as design tools but just as drawing tools, and there are other domains to be explored in design research.

The second tries to avoid both sketches and CAD tools limitations by proposing parallel techniques, like SBIM (Sketch Based Interfaces for Modeling, for a complete survey, see [12]) or Virtual Reality systems including a sketch input. These systems deal with "quick and dirty" representations but are not linked to designers' work tools and practices, and being so do not answer the professionals' expectations [12].

Finally, the third gives up on traditional (and sometimes obsolete) freehand sketch techniques and focuses on CAD tools, sometimes augmented by haptic or immersive interfaces.

To reach our goal, that is to say to gain insight into design tools evolution and to get closer from current professional realities, we prefer to first put aside such "techno" decisions. Our reasoning is built on 3 main phases: first to take an "anthropo-based" standpoint, then to focus on mediating objects and finally to study the tools' complementarities. Dorst [13] proposes the same type of approach and bases it on 4 main steps: observe - describe - explain-prescribe.

\section{First Phase: Addressing the Question from an "Anthropo-Based" Standpoint}

In order to keep the actors of design activity at the core of our research, we adopt a comprehensive ergonomic approach. Ergonomics provide sound methods to conduct empirical in situ studies and adopt a multidisciplinary point of view. The aim of these "anthropo-based" methods is to analyze all concerned actors, without focusing only on obvious "end-users". These 
methods enable us to study the designer's profile, the definition of the real and prescribed tasks, the strategies, the required competences, and so on. Ergonomics particularly fits to the logic of business, reliability, productivity and competition inherent to design environment. This discipline also enables us to take into account two major impacts: the impact of new technologies and the impact of work contexts.

As far as new technologies are concerned, as we underlined before, there is a need to evaluate how designers have been able to adapt their work and competences since CAD tools' introduction. The importance to consider practices' evolution is underlined by Dorst [13]: "likewise, we are surprised that the tools we are developing are not widely used in design practice .... The momentous changes in design practice that are taking place at this time do not seem to influence design research at all. But they should ...".

Regarding the impact of the work contexts, as suggested by McGown and Green [14], the linear models of design processes developed in design engineering or psychological studies need to re-introduce the "loops" of actions. There is as well a need to put forward the external constraints of context $[13 ; 1]$. We would even emphasize the multiplicity of elements by putting it in the plural: contexts of work, of cooperation with colleagues, of physical environment, of types of project.

\section{Second Phase: Focusing on "Mediating Objects"}

Our interest goes to the evolution of design tools' usages in real practices. As a reference of analysis, we consequently choose to focus on the "mediating tools" of the design activity. We even extend our focus to the "mediating objects". In addition to the physical tools (the pen; the computer, the prototyping machine, ...), the mediating objects include the external representations linked to them (respectively the free-hand sketch; the 3D model or print, the physical model, ...). By considering them this way, we try to avoid a general misunderstanding that can occur between "tool" and "representation". For CAD for instance, a polysemy can occur between (i) the tool itself, with its Human-Machine Interface, its modalities of use and sharing, the techniques of 3D modeling (box modeling; mesh or surface modeling: extrude-edge;...); (ii) the cognitive artifact, visual basis of a virtual design (in 2D or 3D) or (iii) the external representation, physical production as $2 \mathrm{D}$ prints or $3 \mathrm{D}$ prototypes. This polysemy commonly appears during designers' verbalizations and it reveals the multiplicity of significations that an "object" can have.

In order to study these mediating objects, we adopt the instrumental theory as theoretical framework. Developed by Rabardel and Vérillon [in 
15] this theory introduces the notion of instrument as the combination of an artifact (material, symbolic, cognitive, or semiotic) and one or more associated schemes. The artifact can be commonly defined as the physical part of a tool. On the other hand, the scheme is the result of "a construction specific to the subject, or through the appropriation of pre-existing social schemes" [16]. The example usually given is the hammering scheme, ordinarily associated with a hammer, that could be adapted to a shifting spanner in case of necessity. Both poles of the instrumental entity (the artifact and its utilization scheme(s)) act together as the mediator between the subject and the "object of his activity" [16], defined here as the "act of designing", Figure 1.

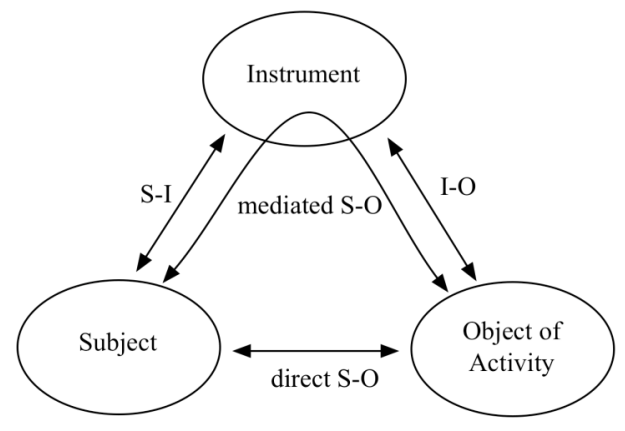

Fig. 1 IAS Model, "Instrumented Activity Situations", by Rabardel \& Vérillion, 1995 [15]

Among all the possible approaches of Human-Machine relationships, we adopt this "mediation of the activity through the usage of objects". It helps us to put forward the actual characteristics of industrial designers' work through the use, the sequence of use and the modifications of "objects" inputs.

Third Phase: Undoing the Comparative/Dichotomous approach to the benefit of the study of Complementarities

As we underlined before, new digital design tools and modified contexts of work inevitably affect each other. Some authors argue that the schemes of use of these new tools are in contradiction with the traditional schemes (free-hand sketch schemes), this maladjustment being the cause of a constraining work environment [17]. In contrast, we would suggest not to consider two opposite profiles of designers working in dichotomous worlds and using incompatible schemes (traditional schemes vs. CAD 
tools schemes), but rather to consider a flexible mid-way profile taking advantages of the objects' diversity and complementarities (in regard to the appearing constraints and the contexts).

What could be seen as a paradox - the use of tools that seem inappropriate - will be showed later as the human capacity to adapt to a constraining environment, or to deviate the tools from their original usages.

These three theories (the last one remaining to be proved) structure our study of design tools' evolution as well as our research methods that are presented in the next paragraph.

\section{Method}

A two-stage method is proposed. Both aim at understanding the reciprocal impacts between the contexts and the mediating objects, as well as analyzing their consequences on work practices' evolution. On top of that, the first stage more particularly aims at (i) listing the designers' work habits and (iii) defining global work profiles. The second detailed stage tests the complementarity thesis and deepens the mediating objects' analysis.

\section{Twelve Conversations to list the Context Factors: An Exploratory Research}

A single research move is not enough to explore all the factors that could exhaustively explain the design tools' evolution, and consequently there is a need to select a few of these factors. This exploratory research tries to embrace the diversity of their origins to better manage this selection.

We organized twelve conversations with designers representing the diversity of the design profession. The representativeness of the sample is exhaustive, since all the designers have different careers (textile designer; light designer; industrial designers; architect/interior designer; furniture designers; teacher in design school; designer specialized in virtual graphic creations; designer of advertising structures and stands).

Among them, 7 can be considered as experts (more than 5 years of business experience in the design field, have been exposed to numerous situations individually or as part of the team); 5 as juniors (less than 5 years of experience). Another type of expertise level can also be underlined: the expertise in CAD tools. Indeed, among the 5 juniors, 4 are 
considered as experts in CAD tools, and among the experts, only 2 out of 7 are able to use these tools.

Nine of the twelve designers are coming from the same design school. This could be seen as either a limitation of the sample representativeness or the possibility to fix the education variable (that could also explain the expertise level toward CAD tools).

The interview protocol is "semi-directive" and is structured on a retrospective analysis of past projects. The retrospective analysis consists in asking to the designers to choose two projects they consider as representative of their work (achieved or not). They collect all the graphical/digital/physical traces they can find back from these projects. Asking the designers to refer to these real traces helps to found the verbalization on tangible memories and tends to avoid biased speeches. The questions can be classified in 5 themes: (i) general questioning for the sample definition; (ii) presentation of the design process of both selected projects (methods, inspiration sources, collaborations,...); (iii) operative methods of the everyday work; (iv) use of design tools (and representations) and (v) modalities of collaboration.

\section{Data Analysis}

The data gained through these 12 interviews is classified in several context factors, each of them presenting a double variable. Five of them are turning to profit in this paper:

Expertise level in design field: Junior / Expert;

Exploitation of CAD tools: Him(her)self / Sub-contract;

Use of CAD tools: In production phase only / In preliminary design and production phase;

Recourse to free-hand sketching: Yes / No;

Possibility of co-working with a draughtsman: Yes / No.

This classification enables us to do a descriptive and quantitative (but preliminary) counting and to classify the 12 subjects in their corresponding variables.

\section{Results of the interviews}

We present a few conclusions that emerge from this exploratory phase. For further contents, please refer to [18]. The interviews' results are summed up in the following matrix, Table 2 . 
Table 2 Each number, situated at the crossing of two diagonals, represents the number of designers positively satisfying to the two variables the diagonals are referring to

\begin{tabular}{l|l} 
CAD Use & $\mathrm{CAD}$ in production phase only \\
\hline $\begin{array}{l}\text { Exploitation } \\
\text { Experience in } \\
\text { design field }\end{array}$ & Possiblity to co-work with draughtsmen \\
\hline $\begin{array}{l}\text { Recourse to } \\
\text { free-hand } \\
\text { sketching }\end{array}$ & CAD sub-contracting \\
\hline
\end{tabular}

A first difference appears between juniors and experts (in design field), as far as CAD use is concerned. A majority of juniors, educated to CAD tools during their training, does not hesitate to use this design tool as soon as possible. Less interested or trained to CAD tools, experts only use them during the detailed design phase and under time, market and economic pressure. The verbalization makes appear a second difference. The recourse to CAD tools depends on the possibility of co-working with a draughtsman. Juniors usually work individually and do not have access to larger structures introducing draughtsmen. On the other hand, experts have more possibilities of working in such structures, and some of them indeed co-work with them. On top of that, a link between the experience level and the fact of sub-contracting (or not) the CAD detailed phase could exist.

There is no clear link between the use of free-hand sketching and the personal exploitation made of CAD tools. On the other hand, designers that argue not being in need of free-hand sketching never sub-contract the use of the CAD tools. In a similar manner, the link between the CAD tools' use and the recourse to free-hand sketching reveals the remaining importance of both design tools, as well as the impact CAD tools have on work habits and more traditional tools.

From these preliminary results, we propose a first prognostic in terms of three designers' profiles (table 3). This table sums up (i) the recourse to each type of tool in regard to the design phase; (ii) the relation maintained with free-hand sketches and CAD tools and (iii) the relationship with the potential draughtsman. 
Table 3 Proposition of three designers' profiles

\begin{tabular}{|c|c|c|c|}
\hline Profile number & $\begin{array}{l}\text { Supposed relationship } \\
\text { with sketches }\end{array}$ & $\begin{array}{l}\text { Supposed relationship with } \\
\text { CAD tools }\end{array}$ & $\begin{array}{l}\text { Supposed } \\
\text { collaboration with } \\
\text { the draughtsman }\end{array}$ \\
\hline $\begin{array}{l}1-\text { Sub- } \\
\text { contracting } \\
\text { CAD phase }\end{array}$ & $\begin{array}{l}\text { - during preliminary } \\
\text { design phase } \\
\text { principally } \\
\text {-iterative loops } \\
\text { see-transform-see } \\
\text { conversation with the } \\
\text { sketch }\end{array}$ & $\begin{array}{l}\text {-minimal } \\
\text { •evaluation; checking; } \\
\text { communication }\end{array}$ & $\begin{array}{l}\text { - distributed design } \\
\text { - negotiation ? }\end{array}$ \\
\hline $\begin{array}{l}2 \text { - Preliminary } \\
\text { iterative design } \\
\text { using sketch } \\
\text { and CAD tools }\end{array}$ & $\begin{array}{l}\text { - during preliminary } \\
\text { design and production } \\
\text { phases } \\
\text { - iterative loops } \\
\text { - see-transform-see } \\
\text { conversations with } \\
\text { both representations }\end{array}$ & $\begin{array}{l}\cdot \text { during preliminary design } \\
\text { and production phases } \\
\text {-iterative loops } \\
\text {-see-transform-see } \\
\text { conversation with CAD } \\
\text { representations }\end{array}$ & $\begin{array}{l}\text { - collaboration } \\
\text { - co-design }\end{array}$ \\
\hline $\begin{array}{l}3 \text { - Preliminary } \\
\text { iterative design } \\
\text { using the CAD } \\
\text { tools only }\end{array}$ & $\begin{array}{l}\text { - minimal } \\
\text { - reminder sketch } \\
\text { - crystallization sketch }\end{array}$ & $\begin{array}{l}\bullet \text { during preliminary design } \\
\text { and production phases } \\
\bullet \text { iterative loops } \\
\text { - see-transform-see } \\
\text { conversation with CAD } \\
\text { representations only }\end{array}$ & $\begin{array}{l}- \text { No information at } \\
\text { this stage. }\end{array}$ \\
\hline
\end{tabular}

This exploratory research enables us to attest some of the impact factors that contribute undoubtedly to the evolution of designers' practices:

The impact of CAD tools introduction on more traditional tools (here, free-hand sketches), as already underlined by many authors;

The impact of contexts elements on the use of mediating objects: external constraints, time-pressure, customers' expectations, levels of experience in design field and expertise in CAD tool usage;

- The impact of the chosen mediating objects on the design process

- The impact of a new type of collaboration with the draughtsman

The second stage, presented next, enables us to go on with the exploration of these factors' impact on our research questions and to refine the profiles definition in regard to the "complementarity" thesis. We decided to take advantage of the anthropo-based approach in order to study industrial designers in their real working context. Indeed, referencing to a specific domain is more efficient than exploring a wide field of design [12]. Consequently we focus on an industrial design team (i) made up of designers with diverse profiles; (ii) collaborating with draughtsmen, and (iii) working in contexts presenting rich variability. 


\section{Detailed Research}

A design team hosted us for two months in situ observation. This team is active in the field of heating devices, and is acknowledged for its high aesthetic and high quality products. The team is composed of 5 designers (all experts in the design field, and among them 3 with high expertise in CAD tools) and 3 draughtsmen (all experts in CAD tools; one expert in the specific design field, 2 juniors).

The observer stayed 8 hours a day inside the open-space office. She was allowed to interview the subjects and capture (recording or filming) every stage of the current designs and all the interactions (between the team, between members of the team and extern members such as the CEO or the prototypists). This type of in situ intervention presents three advantages. First, it avoids the limitations of a non-realistic lab situation by providing the essential contexts elements. Second, it avoids the possible disturbance of a think-aloud protocol. Third, it enables a qualitative approach of the fine-grained details of the design process that would be ignored in a more quantitative study. These details indeed constitute a stumbling block of the whole project rationale but remain very punctual.

On top of the 8 interviews (based on the same semi-directive and retrospective analysis protocol than the exploratory research) we selected 5 different products as a basis of study. These projects were selected for their representativeness. They indeed provide a good range of use of mediating objects, and present diverse states of progression (formal, technical and productive). They provide a relatively complete view of the design process and methods without following a 2 or 3 years complete project.

\section{Data Analysis}

Collected Data (interviews based on retrospective analysis as well as in situ observations) has been coded [see 18]. This coding aims at gaining information about the tools' and representations' uses in relation to what occurs as "external" factors. Further explanations have been gained (through questioning) in case of uncertainty.

The code applies to distinct units of designing actions. One action is defined as soon as the mediating object changes. This change usually goes with a shift in design process (shift from one support to another, one piece to another, one constraint evaluation to another,...). This coding scheme is exploited to construct the timelines of the projects (fig 3). Timelines aim at reproducing the design process of the 5 selected projects. The $\mathrm{X}$-axis figures the project evolution in time, and represents different time scales since the data proceed from interviews' or observations' coding. The Y- 
axis sums up the various variables of the coding scheme. These variables are classified according to the use of one specific tool (sketch; CAD tool or prototype). For each tool, variables are again classified in different levels: (i) an "utility level" (or function inside the process) answers the question "what is it useful for ?"; (ii) a "cognitive level" designates the designer's cognitive activity: gathering information or knowledge, generating solutions, evaluating or modifying, searching in iterative loops and (iii) a "productive level" lists the type of representations obtained (in terms of content, spatial representation or underlying model). In parallel on the Yaxis appears the modality of collaboration (with whom, for doing what).

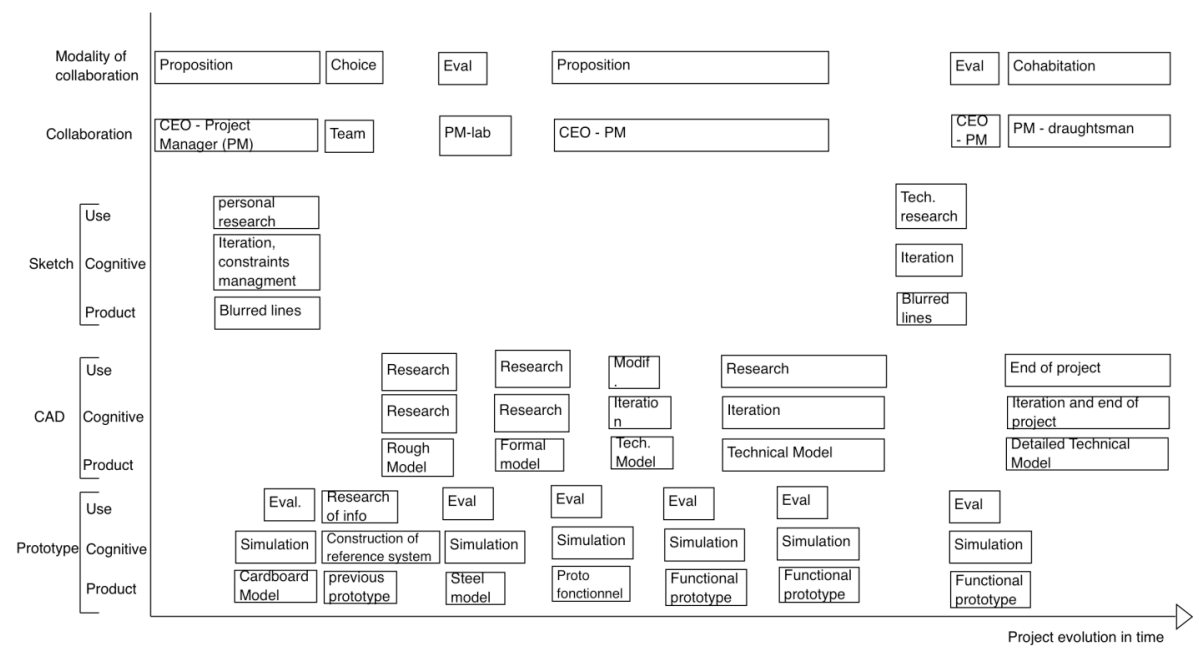

Fig. 3 An example of timeline with some variables (non-exhaustive listing)

\section{Intermediate Observations resulting from Timelines Analysis}

The first intermediate results are provided by a comparison of the five timelines. We observed 5 impacts that external context has on project rationale.

First, the impact of time pressure. Surprisingly the designers can use CAD tools as a "rough" formal tool and then come back to sketches in order to solve a more technical point for instance. Consequently there is a need to distinguish "rough" sketches and "rough" CAD models or representations (that stay ambiguous and support ideation), from "technical" sketches and "detailed" CAD models (that focus on a more specific sub-problem). Simple 3D primitive forms characterize the "rough" CAD models or representations. These models are very quickly created 
without taking care of real dimensions and proportions. As rough sketches, they support the rapid evaluation of more formal or functional ideas.

Second, the impact of project management. Some projects indeed suffered from late decisions; tools maladjustments to the design task, necessity to start again detailed 3D models, CEO choices.

Third the impact of tools selection. Projects are highly structured by several back and forth between different mediating objects (free-hand sketch; CAD tool; prototype). The selection principles depend on the respective properties of both tool and representation. For instance, a sketch on a $2 \mathrm{D}$ print will be used to test dimensions or pieces conflicts; 2D handdrawn perspectives to test a cinematic principle.

Then the impact of collaborations. The projects present various types of collaborations (complex and laborious co-activities; efficient co-design) that modulate tool selection or task repartition.

And finally, the impact of a new co-worker. In parallel with various tasks repartitions, some projects are impacted by the tasks supported by the draughtsmen. They take a great part in the design process. Based on the activity theory, these graphs give insight into tasks distribution between designers and draughtsmen as well as into the role of mediating objects. The first graph presents the global activity of a designer, Figure 4.

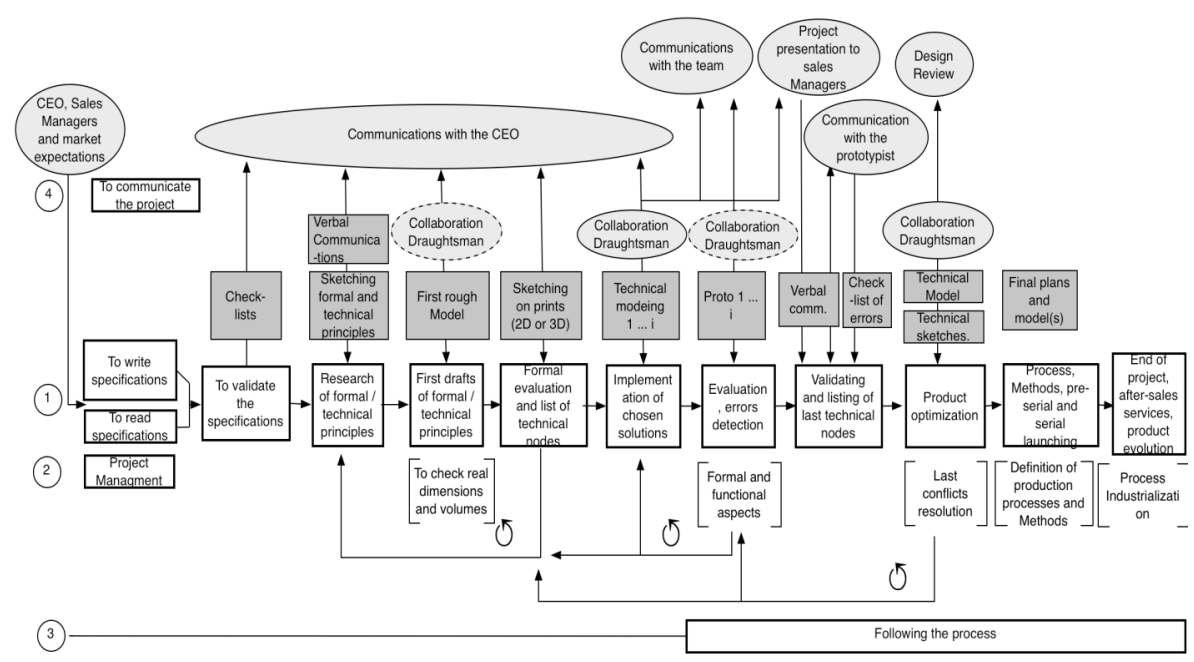

Fig. 4 Designer activity graph, with its multiple layers

This graph is composed of three linked layers. Bold layer indicates the iterative model of the designer activity. The various tasks of a designer are presented. The circular arrows show the multiple points where iterations 
might appear. This "task model" has to be considered as a simplification of the whole activity. The dark grey layer represents the several objects (tools or representations) used all along the process, in mediation between the designer and his/her colleagues or with him/herself. The light grey accounts for the occurrence of a collaboration, with specific persons and according to specific modalities of collaboration, and always through the use of a specific mediating representation. The quasi-systematic exchanges appear in continuous lines, while the occasional ones appear in hatching lines.

Similarly, the draughtsman activity is presented in Figure 5.

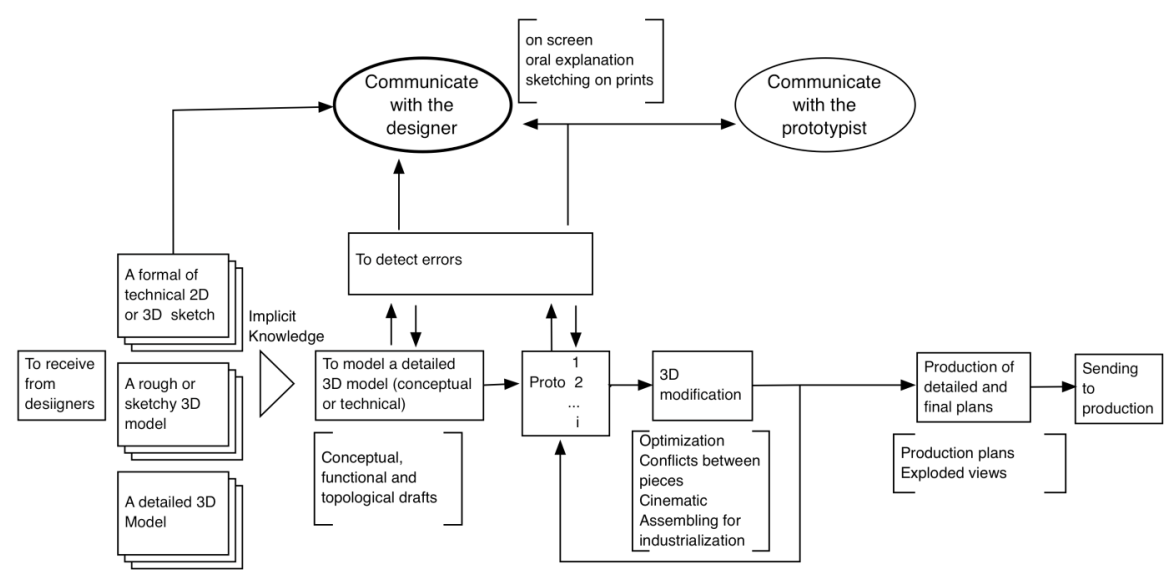

Fig. 5 Draughtsman activity graph, with its multiple layers

This simplified model underlines 4 observations. First, the draughtsman receives from the designer a "rough" representation, that can either be a free-hand sketch, a rough 3D model or a sketch on a print. Second, the main draughtsman's activity consists in detecting the errors and making the project evolve towards a final production plan (through the production of prototypes in this particular design field). Third, his/her activity is deeply impacted by the type of CAD tool used (Pro-Engineer here). $\mathrm{He} / \mathrm{She}$ adapts to this tool's possibilities and limitations. Finally, he/she develops in a few years a great expertise in this specific (and very technical) design field and is totally able to co-operate with the designer in a win-win relationship. 


\section{Results}

This section presents our results in terms of mediating objects' evolution and testing of the complementarity thesis.

\section{Testing the complementarities}

The previous section and the study of the draughtsman's activity graph tends to position the draughtsman not anymore as an executive drawer but as a "designer-draughtsman", which activities are part and parcel of a reassessed design task. The complementarity thesis that we presented above seems even to push further the notion of dichotomy. The next section discusses the corresponding results.

\section{Dichotomy between "Designers that Design" and "Draughtsman that Execute"}

As our results tend to prove, the usual dichotomy (or hierarchy) that links designers and draughtsman disappeared with the recurrent use of CAD tools. Required as early as possible in a project (for economic, time or productivity reasons), these tools are being integrated in designers' tasks, and lead to a new type of collaboration between designers and draughtsmen. A shared referential is being constructed between both actors as a function of the expertise and experience levels. This leads to a situation of "co-design" in the highest and more effective situation. This collaboration was already quoted by some authors, but expressed in a different context. For Lebahar, the draughtsmen's mission is beyond a simple verification of representations. They oppose their own vision of the representation and impose, in a certain way, their own models [1]. Marjchzach and al (1997) and Löwstedt (1993) [quoted in 19] argued at the beginnings of the CAD era that [3D models] were "a technology at disposal which implantation deeply and durably transform the organizations and functioning of a company". These affirmations were right at such times where the CAD tools still were an inaccessible technology for designers but should be reconsidered now, since the situation has evolved. We do not talk about "opposition of representations and models" anymore but about "co-design", and we do not consider the CAD models just as "a technology at disposal" but instead as a complementary tool justifying the introduction of a new co-worker in the design field.

We do not argue that both profiles are strictly equal nowadays. There are still differences that make them complementary. For instance, one 
draughtsman explained that "the question of how to model is more often asked that the question of what to model". The draughtsmen indeed have to develop a specific "way of thinking" to start the 2D or 3D virtual model, that lead them to question the essence of the sketchy representations they receive. Where and what are the "technical nodes" (or difficulties) of the product? What kind of cinematic behavior will the product have? How will it be possible for the prototypists to physically put a screw in such a tiny fold? And last but not least, how will this piece co-exist with the preexisting environment? Draughtsmen even talk about a "programming" of the model to think about before starting the modeling. This programming can be defined as an efficient strategy to quickly represent the 3D model in respect with the future potential modifications and with the hierarchical structure imposed by the software (called "referencement tree"). To conclude with the diversities, we can say that (i) mental transitions (from 2D to $3 \mathrm{D}$ and vice-versa) are different between designers and draughtsmen, i.e. between the author of the sketchy representation and the interpreter; (ii) these specific draughtsmen develop a "Pro-E" way of thinking that can be or not appropriate to mental representations and tools' utilization schemes. In case of maladjustments, the subjects are able to adapt themselves to the constraining environment.

\section{Dichotomy between "Designers that Design" and "Designers that Model"}

Likewise, the dichotomy between "sketch in a preliminary phase" and "CAD in a detailed phase" also have to be revisited. As well as, in extension to what was previously said, the dichotomy between "designers that design" and "designers that model".

The profiles of designers we defined, Table 3, have to be extended. All designers, at least in this particular research, sometimes resort to free-hand sketch, and sometimes to CAD tools. It depends on the particular constraint or task they are dealing with or on the current modality of collaboration. Such constant backs and forths between the tools and representations vary from one designer to another and co-exist efficiently in order to reach the design goal. We suggest that these iterations depend on the level of adaptability of the tools and the schemes of utilization. We also underline that there is not anymore one type of free-hand drawing (the "rough" drawing) and one type of detailed CAD model.

As pointed by our observations and by the verbalizations, the content varies from one rough-sketch to a technical sketch, from a rough-model to a detailed model. They can be all used at any time of the design process. A "mediating objects' graph of use" presented in the next section assesses this observation. 


\section{Going further in the analysis of Mediating Objects}

Figure 6 is the "mediating objects' graph of use" that deepens the understanding of the loops that appear in the usage of the design tools. It enables us to identify on which principles designers shift from one object to another and what are the tools' respective contributions. The $\mathrm{X}$-axis designates the mediating objects appearing in their chronological order, as they appeared in the designers' activity graph previously presented. The Yaxis presents the three levels of tools "functionality", as they appeared previously in the timeline. In parallel of the X-axis, the various "drawings registers" of Lebahar [1] test the evolution of abstraction levels. The first drawings register includes the topological representations. The second regroups the projective representations (no account of real measures and angles but organization of the abstract parts in a figural entity). The third register gathers the Euclidian representations (defined by the geometrical invariants and preventing the deformations, unlike the projective register). Again, inside the graph are presented the several variables (coming from our coding scheme) that sum up the global process of the 5 analyzed projects.

This graph reveals numerous iterative loops. The iterative process is a commonly well accepted concept in design literature, but this graph enables us to enter more deeply into the study of these loops. The study of the objects (or instruments of the mediated activity) shows that in a first loop, relating to a free-hand sketch phase, the sketch stays blurred, dynamic and "open" to creativity. The rough 3D model, when relevant, stays simple, deprived of details and easy to read, as well as also easily modifiable and parametrizable. This loop concludes a first definition of formal concepts. The process then stays relatively linear till the emergence of a more complex model. A new loop can then take place thanks to the emerging constraints (revealed by CAD visual facilities and integration in a pre-existing environment), thanks to interactions with colleagues or consideration of new technical knots. The iteration materializes again through a sketch, but this one presents another type of content. It aims at other objectives: it stays more technical, more focused on the resolution of a specific node and does not consider anymore the global formal aspect. Once the node solved, a model is put together, and this "bottom-up" kind of loops tend towards a more detailed 3D model. Sometimes, a prototype is used to evaluate the project in its real scale and its real mechanisms. This prototype itself reveals new proportions that can be quickly reevaluated through a formal sketch, and so on. 


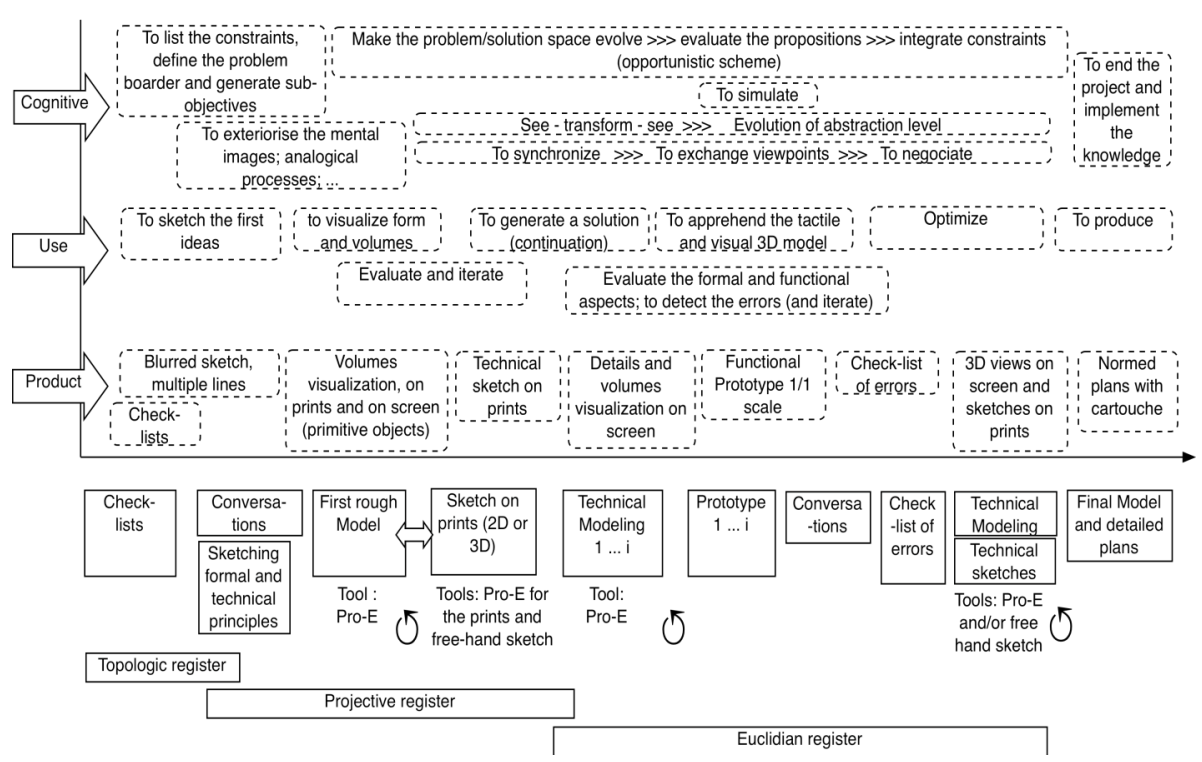

Fig. 6 This graph shows the evolution and extension of mediating objects

Other observations can be drawn from this graph:

- The iterative process' loops match the loops of use of mediating objects: rough sketch $>$ technical sketch $>3 \mathrm{D}$ model (leading to 2D views) $>$ technical sketch $>$ model $>$ prototype $>$ formal sketch;

- The prototypes are also used during tests phases or simulations of the final product;

- Representations' contents evolve in a more continuous way, the abstraction level going towards a more detailed representation [20]. Loops nevertheless remain in the choice of representation type.

The dichotomy is consequently obsolete not only between tools but also between representations. An iterative model combined with an abstraction level evolution is better suited. To this abstraction evolution we can add that the schemes of use (tools schemes and representations schemes) also seem to evolve inside a single project. The repeated appeal to various tools or representations afford the realization of a redundancy effect, which, thanks to Rabardel, allows the subject to make the better choice and achieve a balance between economic and efficient cognitive objectives [15]. Some "tools" are also used simultaneously: for instance the collaboration on prototypes goes with an enormous amount of gestures, while the giving of a personal sketch is always commented. Such a multimodality functioning happens very often during each step of the design process, and contributes to our complementarity proposition. 


\section{Conclusions - Toward Augmented Design Tools Closer to Real Practices}

The approach of real design practices through mediating objects enabled us to establish the relevance of the complementarity approach when considering co-workers, tools and representations in a design team. We presented the impact of tools on elements of contexts and vice-versa, as for instance the impact of time pressure on tool selection. We also underlined the need to focus not only on "obvious" end-user actors, but to widen our field studies to all practitioners that impact in a certain way the process. There are not dichotomous profiles but flexible ones, actors adapting their work habits to the contexts. Ergonomics provide researchers sound methods to analyze the profiles, the various contexts and the adaptations in order to dedicate efficient specifications.

The usage of traditional or CAD tools has significantly evolved these past few years, and their respective impacts lead to the extension of what is usually called the "preliminary design". From now on we suggest that CAD tools could be considered as potentially effective also in this part of the process if considered jointly with sketches.

The use of sketches is also expanded since they can help make technical decisions that come out from conceptual design. Both tools offer respective qualities since they are deviated by users, adapting to appearing constraints. A better combination of design tools advantages (in terms of schemes of use, functions and models of representations as well as interfaces) could lead to an interesting design support system.

The presented results deserve to be enriched by complementary observations, in other design teams creating other products (other scale, other relation to the human body) and working with other CAD tools for instance. These futures researches will lead to the definition of more technical specifications for the design of an industrial design support tool that could contribute to free-hand sketches' and CAD tools' facilities by taking advantage of their complementarities.

\section{References}

1. Lebahar J-C (2007) La conception en design industriel et en architecture. Désir, pertinence, coopération et cognition, Eds Lavoisier

2. Cross N (2000) Strategies for Product Design, 3d Ed. N. Cross. The open University, Milton Keynes, UK, Ed. Wiley 
3. Visser W (2006) The cognitive Artifacts of designing. London, Ed. L. Erlbaum

4. Schön DA, Wiggins G (1992) Kinds of Seeing and Their Functions in Designing-Design Study 13(2): 135-156

5. Goel V (1995) Sketches of Thought, Bradford MIT Press, Cambridge

6. Ullman DG, Wood S, Craig D (1989) The importance of drawing in the mechanical design process. NSF engineering design research conference

7. Suwa M, Purcell T, Gero J (1998) Macroscopic analysis of design processes based on a scheme for coding designers' cognitive actions. Design Studies 19(4): 455-483

8. Bilda Z, Gero J (2005) Does sketching off-load visuo-spatial working memory? Studying Designers '05. JS Gero \& N Bonnardel eds, Key Centre of Design Computing and Cognition, Univeristy of Sydney, Australia

9. McGown A, Green G (1998) Visible ideas: information patterns of conceptual sketch activity. Design Studies 19(4): 431-453

10. Robertson BF, Radcliffe DF (2009) Impact of CAD tools on creative problem solving in engineering design-CAD Elsivier 41(3): 136-146

11. Mitchell WJ, Inouye AS, Blumenthal MS (eds) (2003) Beyond productivity: information technology, innovation and creativity. National Academic Press

12. Olsen L, Samavati FF, Sousa M, Jorge JA (2009) Sketch-based modeling: A survey. In Computers and Graphics 33: 856-103

13. Dorst K (2008) Viewpoint-Design research: a revolution-waiting-to-happen, Design Studies 29: 4-11

14. Howard TJ, Culley SJ, Dekoninck E (2008) Describing the creative design process by the integration of engineering design and cognitive psychology literature, Design Studies 29: 160 - 180

15. Rabardel P (1995) Les hommes et les technologies, approche cognitive des instruments contemporains. Paris : Armand Colin

16. Béguin P, Rabardel P (2000) Designing for instrument-mediated activity Scandinavian Journal of Information Systems

17. Béguin $P$ (1997) Le schème impossible, ou l'histoire d'une conception malheureuse. Research innovation revue 10(Quadrature) 21-39

18. Elsen C (2009) Extension \& modulation of mediating objects' use in industrial design. Master Th. Work \& Society Sc, Ergonomics Research ULg-CNAM, Paris

19. Béguin P (1996) De la complexité du problème à la complexité entre les individus dans les nouvelles stratégies de conception - Actes du colloque de l'école d'architecture de Marseille-Lunigny

20. Rasmussen J (1990) Mental models and the control of action in complex environments. Mental models and human computer interaction 1. (Ackerman D., Tauber M.J. eds) Elsevier, Holland 